Bull. Mater. Sci., Vol. 29, No. 5, October 2006, pp. 449-456. () Indian Academy of Sciences.

\title{
Rheology and structure of aqueous bentonite-polyvinyl alcohol dispersions
}

\author{
$S$ İşÇ $\dot{I}^{\dagger}$, C H ÜNLÜ, O ATICI* and N GÜNGÖR ${ }^{\dagger}$ \\ Department of Chemistry, ${ }^{\dagger}$ Department of Physics, Istanbul Technical University, 34469 Maslak, Istanbul, Turkey
}

MS received 15 February 2006; revised 10 July 2006

\begin{abstract}
The influence of polymer on flow behaviour of Balikesir, Turkey bentonite dispersions (2\%, w/w) was studied for non-ionic polymer, polyvinyl alcohol (PVA). In a range of $3.3 \times 10^{-6}-3.3 \times 10^{5} \mathrm{~mol} / \mathrm{l}$, PVA was added to the bentonite dispersions in different concentrations and its behaviour was observed on rheology parameters. Thixotropy was detected by a hysteresis loop of the flow curves. The data were interpreted taking into account the interactions of colloidal clay particles, bentonitic clay concentrations, structure, and concentrations of added PVA. The particle size analysis was explained by surface orientation of PVA to the clay particles dispersed in aqueous solution. Zeta potential determination also emphasized that PVA molecules got attached on the face and edge surface of clay particles. The morphology of bentonite dispersions was analysed by scanning electron micrograph (SEM). FTIR studies carried out in parallel to rheology studies showed that hydrogen bonds were formed between surface of the clay, and absorbed PVA molecules and adsorbed water. The presence of PVA did not prevent extensive swelling of bentonite.
\end{abstract}

Keywords. Bentonite-polyvinyl alcohol dispersions; rheology; zeta potential; particle size analysis; SEM; FTIR studies.

\section{Introduction}

Clay is a natural raw material that has been used for various purposes since ages and its dimension is under $2 \mu \mathrm{m}$. Montmorillonite is a member of smectite group clay minerals. Bentonites have a high content of montmorillonite and a less amount of other clay minerals. Nowadays, many different industrial branches such as ceramics, paper, rubber; clarification of water, wine, soaps and cleaning and polishing of compounds, drug industry are using these materials.

Bentonite group minerals show a colloidal structure in water due to their internal structure and small particle size. They have large adsorption capacity for polymer compounds and surfactants due to their unique crystal structure (O1phen 1977; Hunter 1986).

The determination of rheological properties of clay-water systems is very important for its characterization. Clay dispersions have colloid structure. The control of the rheological properties of these systems is not only important from a technological but also from a scientific point of view. The rheological behaviour of the system is determined by a mutual effect of attractive and repulsive forces between clay particles, which interact with each other through Coulombic and Van der Waals forces. As a result of these

\footnotetext{
*Author for correspondence (atici@itu.edu.tr)
}

interactions edge-to-edge (EE), edge-to-face (EF) and face-to-face (FF) combinations may be obtained. These simple modes of the particle interactions were found to be rather practical in understanding the stability and the rheological behaviour (Olphen 1977). These interactions can be changed to gain the desired properties with the addition of various electrolytes, polymers, surfactants, and organic matters. There are numerous studies related to these topics (Cameron 1977; Heath and Tadros 1982; Tadros 1987; Lagaly 1989; Güven 1992; Ece et al 1999; Luckham and Rossi 1999; Alemdar et al 2000; Neaman and Singer 2000).

The rheological parameters (viscosity, shear stress, Bingham yield value) of clay dispersion can be used to characterize particle-particle interactions. The polymers that have been added to the bentonite dispersions interact with the clay particles, according to their ionic or non-ionic character. The ionic polymers induce electrostatic interactions, but the non-ionic polymers are adsorbed on the surface by steric interactions. Polymer concentration, molecular weight, hydrolysis degree of polymer, functional groups of polymer, clay particle's size, shape, and surface charge, clay concentration in dispersion, clay's $\mathrm{pH}$, and temperature are effective factors when clay particles interact with the polymers.

In this study, changes in flow properties under the influence of PVA polymer additions at different quantities were investigated in the activated Balikesir, Turkey ben- 
tonite dispersions. The data were interpreted taking into account the interactions of the colloidal clay particles. The interactions between bentonite and PVA were also studied by using infrared spectroscopy.

\section{Experimental}

\subsection{Materials}

The clay sample was obtained from the bentonite deposits in Balikesir, Turkey (Marmara Konkurt Co.). Chemical composition of the sample was determined by atomic adsorption spectrophotometer (Perkin Elmer 3030 model) and silica content was determined gravimetrically. The sample had the chemical composition (wt \%): $\mathrm{Al}_{2} \mathrm{O}_{3} 9 \cdot 30$, $\mathrm{SiO}_{2} 60 \cdot 90, \mathrm{Fe}_{2} \mathrm{O}_{3} 1.77, \mathrm{Na}_{2} \mathrm{O} 1.41, \mathrm{CaO} 2 \cdot 12, \mathrm{MgO} 4.72$, $\mathrm{K}_{2} \mathrm{O} 0 \cdot 40$. Analyses indicated dioctahedral structure of montmorillonite with minor amounts of illite, quartz and feldspar. Polyvinyl alcohol (Sigma, Germany) is a mixture of synthetic polymers produced by the polymerization of vinyl acetate and partial hydrolysis of the resulting polymer's acetate groups $\left[-\left(\mathrm{CH}_{2} \mathrm{CHOH}\right)_{n}-\left(\mathrm{CH}_{2} \mathrm{CHOCOCH}_{3}\right)_{m}-\right]$. Chemical and physical properties of commercial polyvinyl alcohol (PVA) varied depending on its degree of polymerization and degree of hydrolysis. The degree of hydrolysis was determined as $85 \%$ (Cameron 1977). The average molecular weight was calculated from a single point viscosity value and was found to be $\sim 30,000$ (Lindemann 1971).

\subsection{Methods}

The bentonite particles were dispersed in water and shaken extensively for $24 \mathrm{~h}$. These dispersions were mixed with known concentrations of PVA. Then the dispersions were shaken for another $24 \mathrm{~h}$, and their rheological properties were determined with a Brookfield DV-III+ type lowshear viscometer.

\subsection{Characterization and measurements}

Ore samples were identified as Ca-montmorillonite clay minerals using FTIR analysis methods. FTIR analyses (400-4000 $\mathrm{cm}^{-1}$ ) were performed using Jasco Model 5300 FTIR spectrophotometer on $\mathrm{KBr}$ pellets with a concentration of $0 \cdot 1 \%$. Spectral outputs were recorded either in absorbance or transmittance mode as a function of wave number. The particle size distributions (PSD) of the bentonitic clays were determined by the sedimentation technique method. A photocentrifugal Particle Size Analyser SA-CP2 model Shimadzu, Corp., was used for particle size measurements. Scanning electron micrographs (SEM) were taken using JEOL JSM-840 electron microscope. The specimens were frozen under liquid nitrogen, and then fractured, mounted and coated with gold (300 $⿱$ ) on Edwards S 150B sputter coater. SEM measurements were operated at $15 \mathrm{kV}$. The magnification employed was varied up to $11000 X$. The zeta potential measurements were carried out using a Malvern Instruments, Zetasizer 2000. The optic unit contains a $5 \mathrm{~mW} \mathrm{He}-\mathrm{Ne}(638 \mathrm{~nm})$ laser. In this instrument to make an electrophoretic mobility measurement, laser beams are caused to cross at a particular point in the cell. Particles in the cell were illuminated by these beams. At the crossing point of the beams, Young's interference fringes are formed. Particles moving through the fringes under the influence of the applied electric field scatter light whose intensity fluctuates with a frequency that is related to the particle velocity. The photons detected by photomultiplier are fed to a digital correlator, the resulting function being analysed to determine the frequency spectrum, from which the mobility and hence the zeta potential are calculated. Measured electrophoretic mobilities were converted to zeta potential using established theories. Zeta potential was measured, injecting a small portion into the cell of Zetasizer 2000 instrument at $25^{\circ} \mathrm{C}$ temperature. Before the measurements, all the dispersions were centrifugated at $4500 \mathrm{rpm}$ for $30 \mathrm{~min}$, then supernatants were used for zeta potential measurements.

\section{Results and discussion}

The flow behaviour of any material may be characterized by a consistency curve or flow curve, a diagram relating the shear rate $(\gamma)$ and the shear stress $(\tau)$. When the plot of shear rate vs shear stress is a straight line through the origin, the material is characterized as a Newtonian fluid. For a nonlinear plot, which has an intercept on the $\tau$-axis at zero $\gamma$, the material is called a plastic substance or a Bingham body. According to the Bingham model, slope of the linear part of the flow curve is referred to as the plastic viscosity and interception of the linear portion of the curve with stress axis is referred to as the Bingham yield (stress) value. At low rates of shear, such systems exhibit nonNewtonian flow, which is characterized by a progressive decline in viscosity as shear rate increases. Above a certain value of shear rate flow curve becomes linear. The shear stress vs shear rate curve for clay dispersions is shown in figure 1. These curves are typical of a Bingham pseudoplastic system (Lagaly 1989; Günister et al 2004; Yürüdü et al 2005). The sample dispersions exhibit Bingham plastic behaviour. It can be seen from the figure that Bingham yield value showed little variation. Rheogram is automatically plotted using Rheocal 32 . The graph obtained indicated that the sample had yield point, and was consistent with the Bingham flow model (Lagaly 1989). A Bingham model was applied,

$$
\tau=\tau_{\mathrm{B}}+\eta_{\mathrm{PL}} \gamma
$$

From (1) the yield value $\left(\tau_{\mathrm{B}}\right)$ was obtained by extrapolation of the linear portion of the shear stress-shear rate curve to 

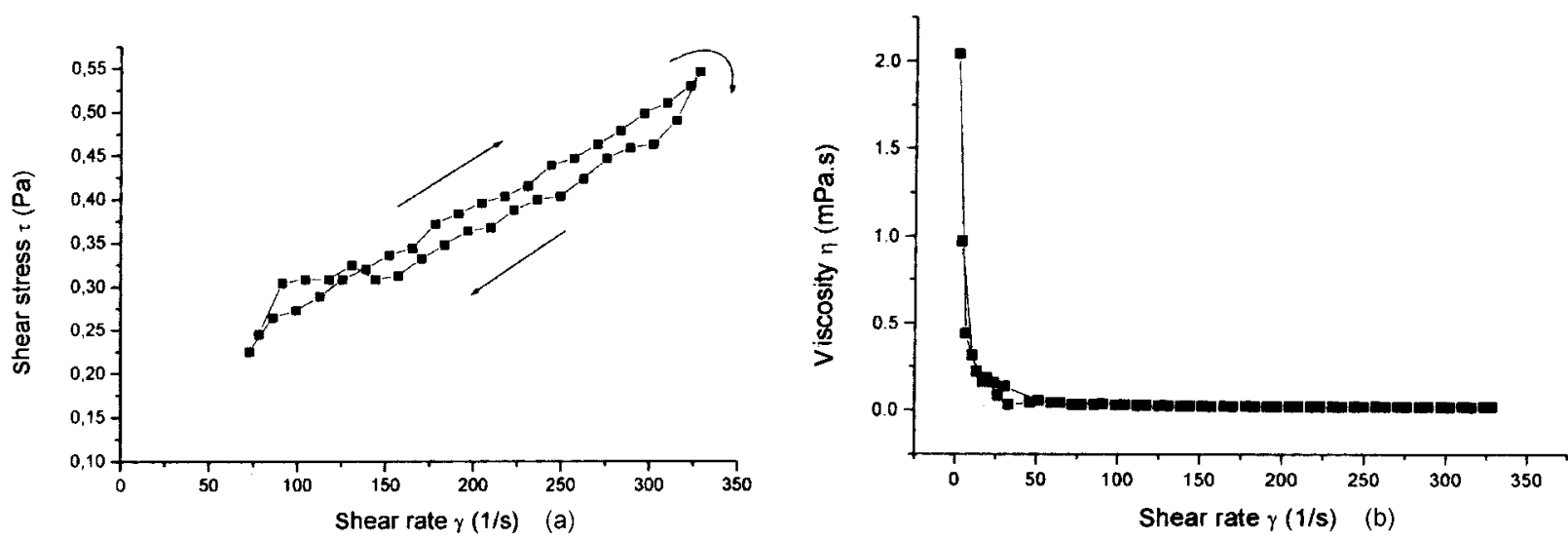

Figure 1. (a) The flow curve of $2 \% \mathrm{w} / \mathrm{w}$ dispersion of Balikesir bentonitic clay and (b) plastic viscosity-shear rate curves of clay dispersions.

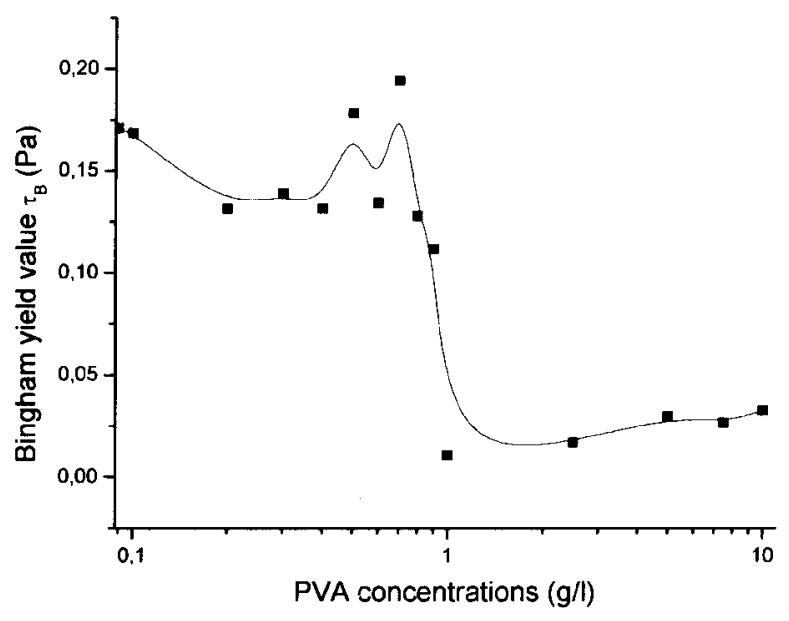

Figure 2. The influence of PVA on the yield value of $2 \%$ (w/w) bentonite water system.

$\gamma=0$, and the plastic viscosity $\left(\eta_{\mathrm{PL}}\right)$ from the shape of the linear portion of the curve. Pseudoplastic flow of colloid dispersions can be described by the Bingham model (Güven 1992). For all samples, the flow curves became linear at shearing rates of $0-350 \mathrm{~s}^{-1}$.

The $\tau=f(\gamma)$ curve (figure 1) for the sample was consistent with the Bingham plastic flow model (Lagaly 1989). This curve was typical of a pseudoplastic system, showing a thixotropic loop. Change of apparent viscosity of the dispersion is shown in figure $1 \mathrm{~b}$ as a function of shear rate. The curve showed a sudden decrease at small shear rates indicating thixotropic properties of the sample. The Bingham yield value was $0.170 \mathrm{~Pa}$ and $0.033 \mathrm{~Pa}$ for clay-water system and clay-water-PVA system, respectively.

PVA is a polymer with non-ionic structure, which is dissoluble in water. Non-ionic polymer does not interact electrostatically with charged clay particles. The polymer

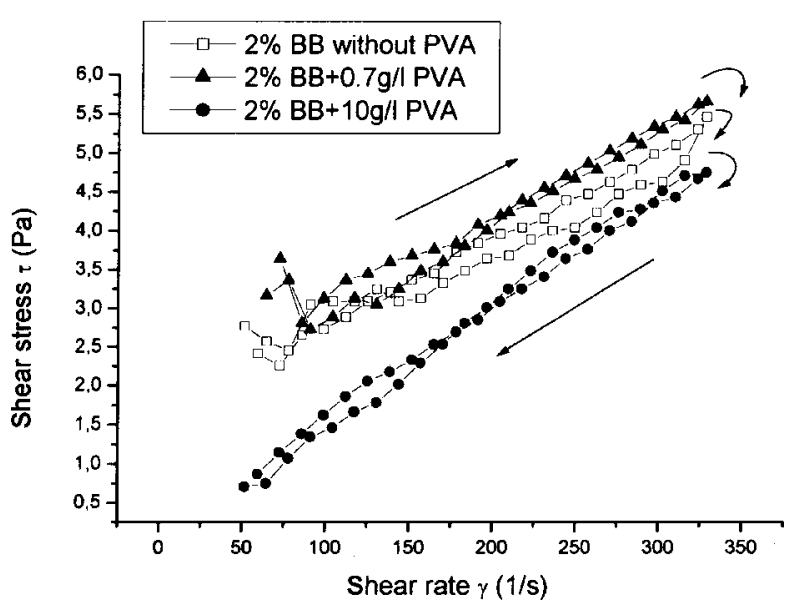

Figure 3. The flow behaviour of bentonite dispersions with/ without polymer.

molecules can attach or anchor on the particle surfaces and into the interlayer. Adsorption of the polymer on charged surface of the clay particles leads to significant modification of the charge distribution in the electrical double layer.

In figure 2, the Bingham yield value of bentonite dispersions was plotted as a function of increasing PVA concentrations. Theory and practice indicated that extrapolated shear stress (Bingham yield value) was a criterion of the particle-particle interactions. When PVA was added to the dispersions, a decrease in initial yield value was observed, showing an interaction between polymer molecules and clay particles. PVA behaved like a salt and decreased the double layer thickness of thin particles. This caused a decrease in electroviscous effect and yield values of dispersions decreased to a minimum $0.4 \mathrm{~g} / 1$ polymer concentrations. The groups existing before the addition 

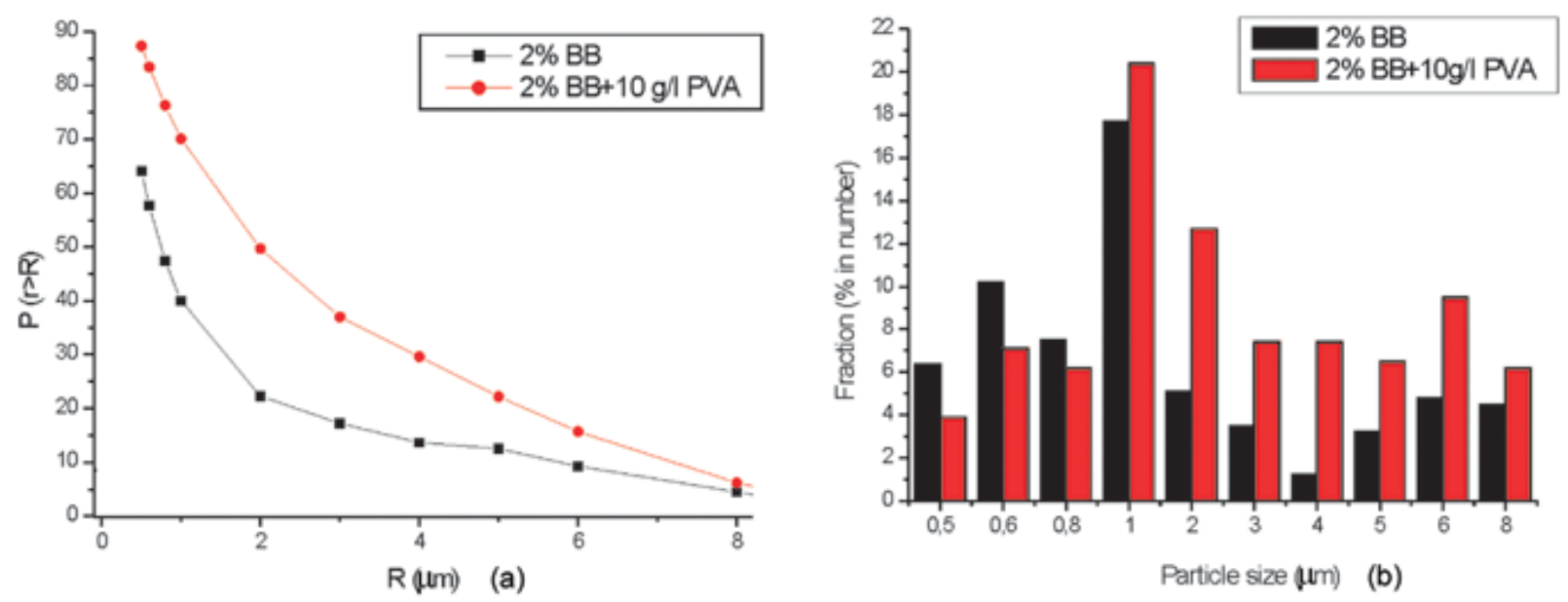

Figure 4. Particle size distribution of $2 \% \mathrm{w} / \mathrm{w}$ of Balikesir bentonite with/without PVA.

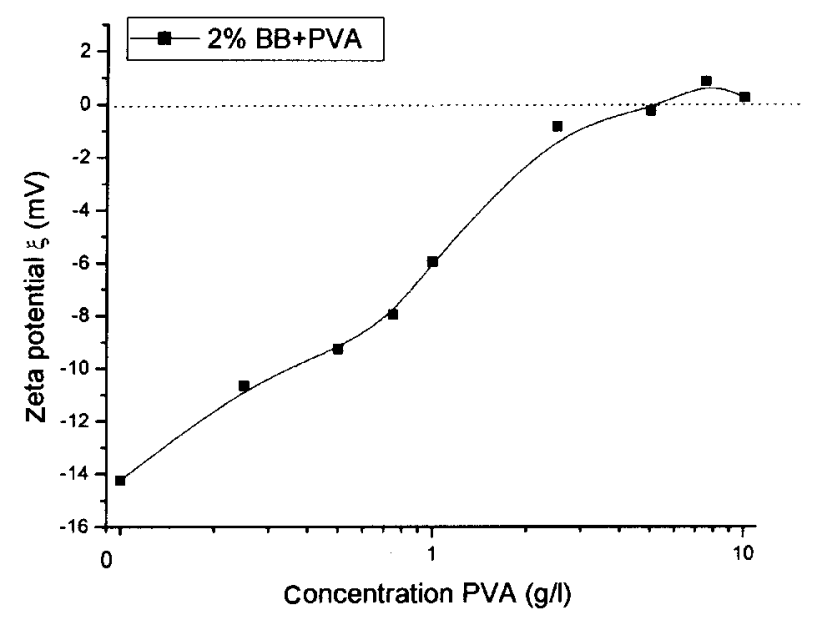

Figure 5. The zeta potential of the bentonite dispersion as a function of PVA concentration.

has been dispersing and the environment can display less resistance against the flow (Tadros 1987; İșçi et al 2004). An increase was observed after addition of $0.5 \mathrm{~g} / 1$ polyvinyl alcohol. The reason was that the bridge flocculation made by two clay particles with their surrounding polymer extensions when they approached each other. The entanglement of adsorbed polymer chains may also occur and result in high system viscosity. The increase of yield value was an indicator of a net structure formed in the dispersions. Further increase in polymer concentration resulted in a reduction in this gelation. This decrease was related to the steric push that occurred between PVA covered clay particles.

Bentonite dispersions are thixotropic and, for that reason, have a wide range of industrial applications. A thixotropic system begins to flow under stirring or vibrating and thickens again when standing. Thixotropy is a time dependent phenomenon. A thixotropic system will change during flow curve measurements by a viscometer, and a hysteresis loop will be obtained when readings are taken subsequently at increasing and decreasing rates of shear (Heath and Tadros 1982; Neaman and Singer 2000).

Hysteresis effect was observed for the bentonite dispersion (figure 3 ). These results suggested that bentonite dispersions were thixotropic. The results indicated that a gradual increase in gelation on addition of PVA polymer reached a maximum at $0.7 \mathrm{~g} / 1$ polymer. This gel-like dispersion showed pronounced thixotropy. Further increase in polymer concentration resulted in reduction in this gelation. These results were in good agreement with the Bingham yield value behaviour of bentonite dispersion.

Measurements of particle size of bentonite, and bentonitePVA dispersion samples showed increased average size of the bentonite-PVA product (figure 4). The stack sizes of bentonite and bentonite-PVA measured by particle size analysis were about $1-1.5 \mu \mathrm{m}$. No particle was found to be bigger than $10 \mu \mathrm{m}$ with/without PVA. Besides, it was also noteworthy that the products with a particle size bigger than $0.5 \mu \mathrm{m}$ on an average with/without PVA, revealed about $64.1 \%$ and $87.3 \%$ fraction in particle number, respectively. This was an indication that the polyvinyl alcohol was loosely bounded and interacted with the surface of colloidal clay particle.

Figure 5 shows the zeta potential values for bentonite dispersion with increasing PVA concentration. The zeta potential is an electrical potential in the double layer at the interface between a particle, which moves in an electric field, and surrounding liquid. The surface charge property can be characterized by zeta potential. The zeta potential, which is an indicator of a push between the particles, increases at the basic conditions by the negative loading of the particles. The zeta potential value of the bentonite dispersion in the absence of PVA polymer was $-14 \mathrm{mV}$. 

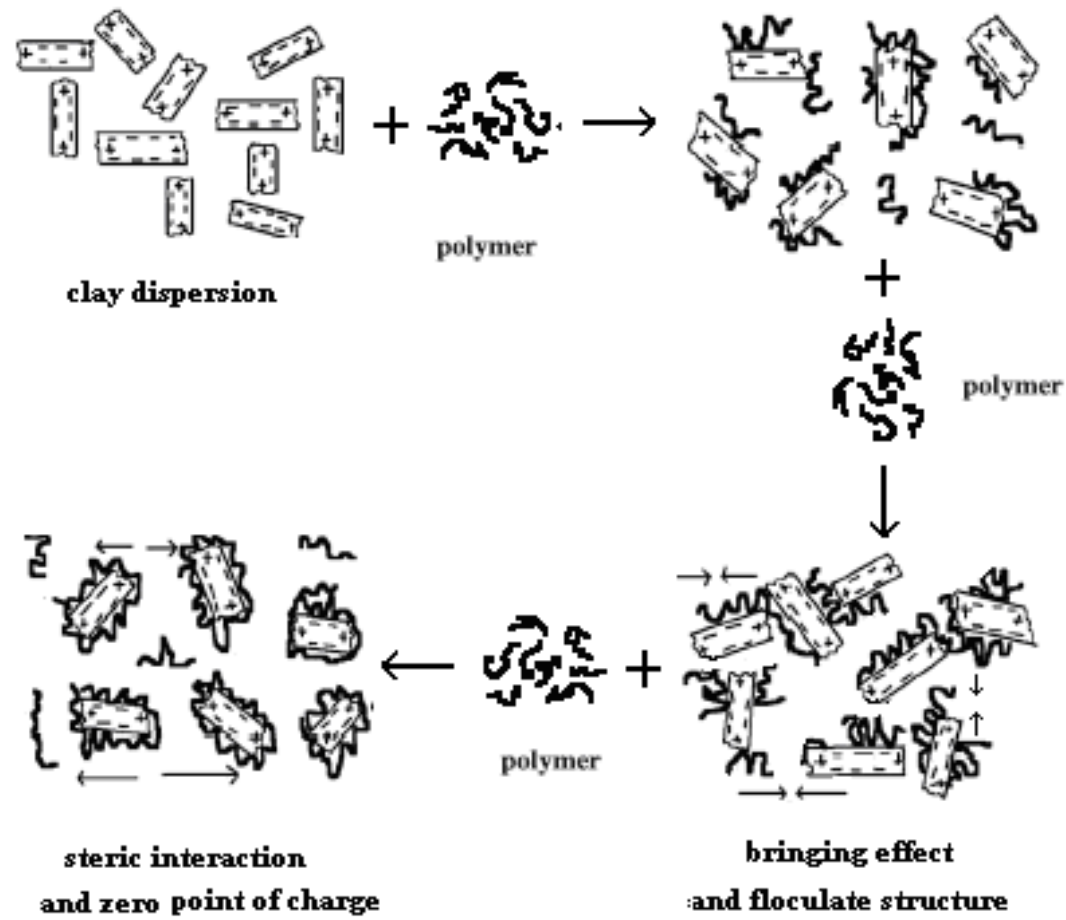

Figure 6. Schematic representation of adsorption of PVA polymer on Balikesir bentonite particles as a function of concentration of polymer.
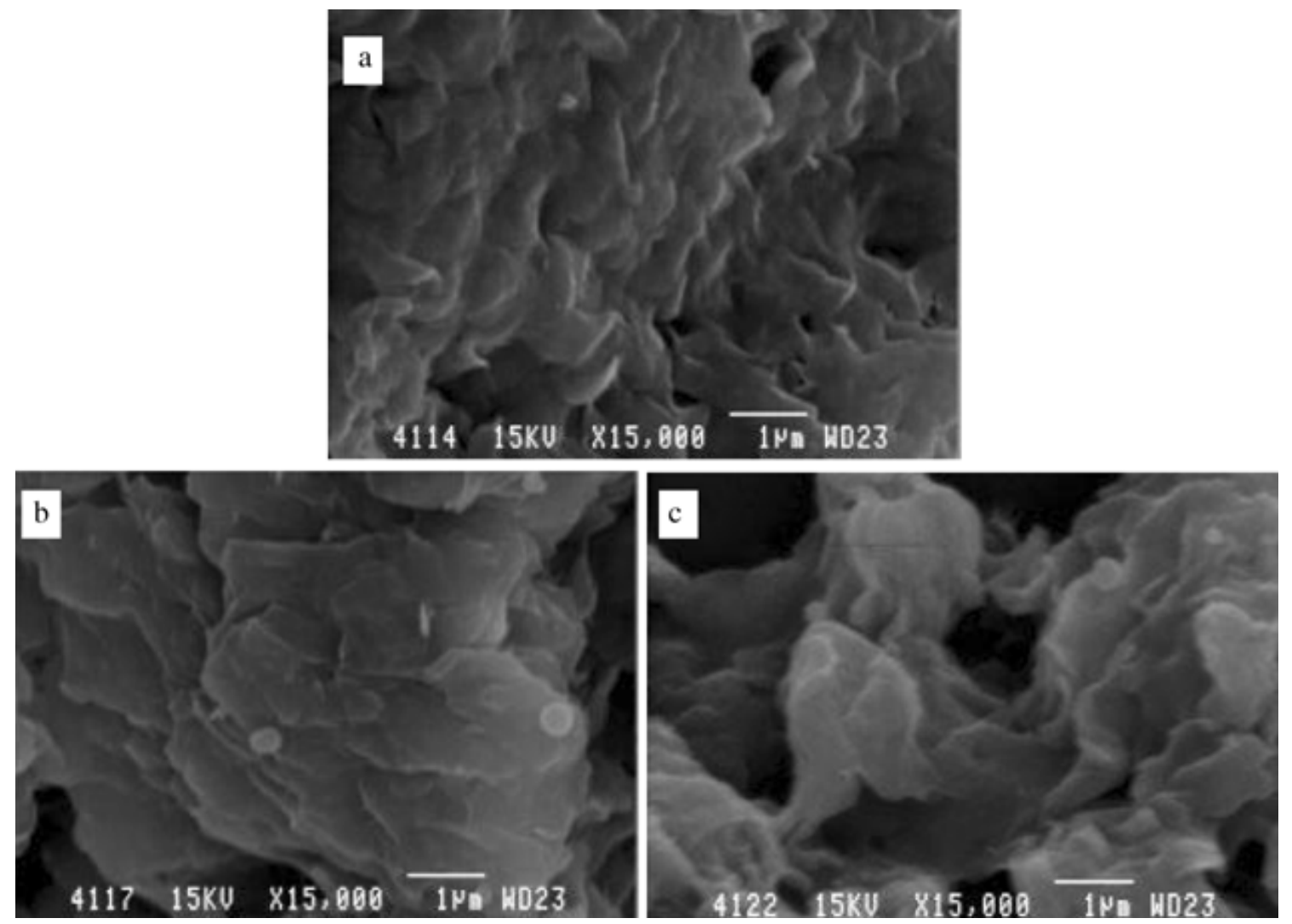

Figure 7. SEM micrographs of a. $2 \% \mathrm{w} / \mathrm{w}$ of Balikesir bentonite without PVA, b. $2 \% \mathrm{w} / \mathrm{w}$ of Balikesir bentonite with $1 \mathrm{~g} / \mathrm{l} \mathrm{PVA}$ and c. $2 \% \mathrm{w} / \mathrm{w}$ of Balikesir bentonite with $10 \mathrm{~g} / \mathrm{l} \mathrm{PVA}$. 


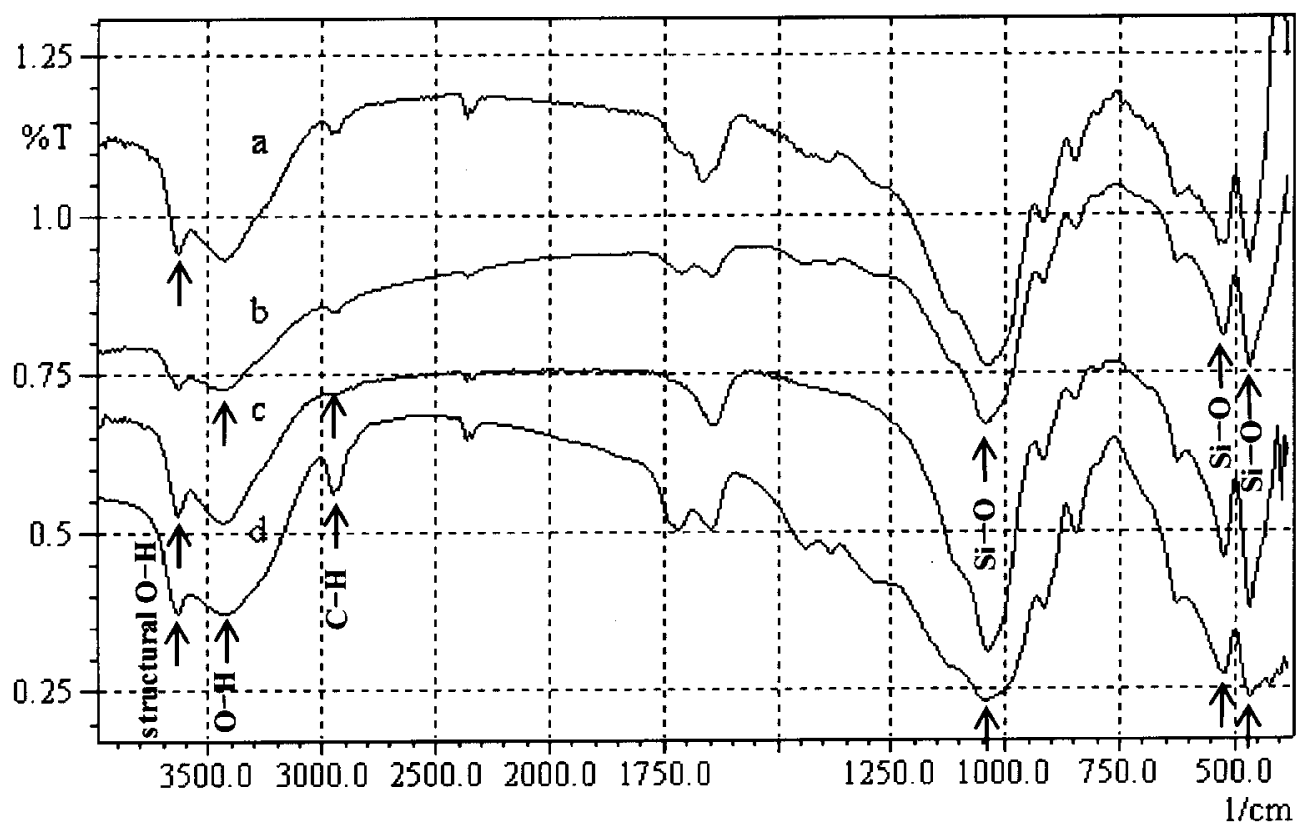

Figure 8. FTIR spectra of a. $1 \mathrm{~g} / 1$ polyvinyl alcohol adsorbed on Ca-montmorillonite, b. $2.5 \mathrm{~g} / 1$ polyvinyl alcohol adsorbed on Ca-montmorillonite, c. Ca-montmorillonite and $\mathbf{d}$. $10 \mathrm{~g} / \mathrm{l}$ polyvinyl alcohol adsorbed on Ca-montmorillonite.

This value determines the system displaying a flocculate structure. The adsorption phenomena of PVA on bentonite particles as a function of concentration of the polymer is schematically presented in figure 6. Increasing concentration of PVA results in a decrease in the zeta potential value of the bentonite dispersions. This decrease in the zeta potential revealed that PVA molecules attached on the net negatively charged clay particles (steric interaction). As a result of the screening of surface charge by the addition of PVA, electrostatic interactions would become less, and there would also be decrease in zeta potential. In figure 6 , as adsorbed amount increased, zeta potential reached zero point, and with further adsorption zeta potential became a positive. The zero point of charge (isoelectric point) of the clay particles was observed at $2 \% \mathrm{w} / \mathrm{w}$ of Balikesir bentonite with $2.5 \mathrm{~g} / 1$ PVA. The electrokinetic measurements have shown that PVA polymer stays on the clay particle surfaces. The effect of PVA on the rheological properties of the sample was correlated with the data of electro kinetics experiments.

Scanning electron microscopic (SEM) pictures of the samples were used for characterization of the bentonite dispersions with different PVA concentrations (figure 7). Direct evidence of intercalated bentonite dispersion can be found in SEM examination of the cross-section of montmorillonite/PVA. In figure $7 \mathrm{a}$, forming different aggregates (heaps) of clay particles with each other could be seen in $2 \%$ clay dispersion. Face-face interactions were in great number in $1 \mathrm{~g} / 1 \mathrm{PVA}$ dispersion (figure $7 \mathrm{~b}$ ).
Polymer coated particles exhibited appearance of layers with one on top of the other. In $10 \mathrm{~g} / 1$ PVA dispersion we could see that the stacked structure was scattering (figure 7c). SEM images were in consistency with the rheological data which were showing decrease of the yield value with decrease in PVA concentration.

Bentonite dispersions with different PVA concentrations were also characterized by FTIR spectroscopy. The peak corresponding to structural hydroxyl stretching at $3628 \mathrm{~cm}^{-1}$ was attributed to bentonite (figure $8 \mathrm{c}$ ). Hydrogen vibrations indicated by a broad peak centred on $3426 \mathrm{~cm}^{-1}$ were assigned to $\mathrm{O}-\mathrm{H}$ stretch and $\mathrm{H}-\mathrm{O}-\mathrm{H}$ deformation peak at $1642 \mathrm{~cm}^{-1}$ with shoulder at $1651 \mathrm{~cm}^{-1}$ also present in the FTIR spectrum of Ca-bentonite. Sharp peak arousal from $\mathrm{Si}-\mathrm{O}$ stretching at $1036 \mathrm{~cm}^{-1}$, and other sharp peak arousal from $\mathrm{Si}-\mathrm{O}$ bending at $521 \mathrm{~cm}^{-1}$ and $467 \mathrm{~cm}^{-1}$ were also observed.

Standard polyvinyl alcohol showed spectral peaks at $3443 \mathrm{~cm}^{-1}$ (OH stretching), 2963, 2928, $2859 \mathrm{~cm}^{-1}$ (alkyl $\mathrm{CH}$ stretching), 1456, $1437 \mathrm{~cm}^{-1}$ (CH bending) and $1098 \mathrm{~cm}^{-1}$ (C-O stretching). The residual acetate groups in the polymer exhibited peaks at $1734 \mathrm{~cm}^{-1}$ (acetate $\mathrm{C}=\mathrm{O}$ stretching), $1377 \mathrm{~cm}^{-1}$ (CH bending) and $1258 \mathrm{~cm}^{-1}$ (acetate $\mathrm{C}-\mathrm{O}$ bending). The FTIR spectra of polyvinyl alcohol adsorbed on Ca-montmorillonite showed additional peaks including 2953, 2926, 2855, 1715, 1439, 1400, 1387 and $1254 \mathrm{~cm}^{-1}$ (figures $8 \mathrm{a}, \mathrm{b}, \mathrm{d}$ ).

The effect of hydrogen bonding on the frequencies of hydroxyl, carbonyl, and other groups, was summarized in 
Table 1. The effects of hydrogen bonding on the hydroxyl, carbonyl and other group frequencies.

\begin{tabular}{|c|c|c|c|c|c|c|}
\hline $\begin{array}{l}\text { PVA } \\
\mathrm{g} / \mathrm{l}(\mathrm{mol} / \mathrm{lt})\end{array}$ & $\begin{array}{l}\text { Structural OH str. } \\
\qquad\left(\mathrm{cm}^{-1}\right)\end{array}$ & $\begin{array}{l}\text { Hydrog. vibr. } \\
\left(\mathrm{cm}^{-1}\right)\end{array}$ & $\begin{array}{l}\text { Carbonyl str. } \\
\left(\mathrm{cm}^{-1}\right)\end{array}$ & $\begin{array}{l}\mathrm{HOH} \text { def. } \\
\left(\mathrm{cm}^{-1}\right)\end{array}$ & $\begin{array}{l}\mathrm{Si}-\mathrm{O} \text { str. } \\
\left(\mathrm{cm}^{-1}\right)\end{array}$ & $\begin{array}{l}\mathrm{Si}-\mathrm{O} \text { bend. } \\
\left(\mathrm{cm}^{-1}\right)\end{array}$ \\
\hline$-(-)$ & 3628 & 3426 & - & $\begin{array}{l}1642 \mathrm{~cm}^{-1} \text { with } \\
\text { shoulder at } 1651\end{array}$ & 1036 & $521 \& 467$ \\
\hline $0 \cdot 2\left(6 \cdot 67 \times 10^{-6}\right)$ & 3625 & 3426 & Noise & $\begin{array}{l}\text { With max. at } \\
1663 \text { broad peak }\end{array}$ & 1036 & $519 \& 465$ \\
\hline $0.4\left(1.32 \times 10^{-5}\right)$ & 3625 & 3424 & Noise & 1663,1642 & 1038 & $521 \& 465$ \\
\hline $0.6\left(2 \times 10^{-5}\right)$ & 3625 & 3426 & Noise & $\begin{array}{l}1642 \mathrm{~cm}^{-1} \text { with } \\
\text { shoulder at } 1659\end{array}$ & 1038 & $521 \& 463$ \\
\hline $0.8\left(2.6 \times 10^{-5}\right)$ & 3627 & 3426 & Noise & $\begin{array}{l}\text { With max. at } 1663 \\
\text { broad peak }\end{array}$ & 1038 & $521 \& 467$ \\
\hline $1\left(3.3 \times 10^{-5}\right)$ & 3627 & 3424 & 1701 & 1640 & 1038 & $521 \& 467$ \\
\hline $2.5\left(8.33 \times 10^{-5}\right)$ & 3627 & 3424 & 1707 & 1644 & 1042 & $523 \& 467$ \\
\hline $5\left(1.66 \times 10^{-4}\right)$ & 3628 & 3622 & 1715 & 1646 & 1042 & $523 \& 465$ \\
\hline $7.5\left(2.5 \times 10^{-4}\right)$ & 3627 & 3420 & 1715 & 1646 & 1042 & $523 \& 465$ \\
\hline $10\left(3.3 \times 10^{-4}\right)$ & 3630 & 3418 & $\begin{array}{l}1715 \text { with } \\
\text { oulder at } 1734\end{array}$ & 1646 & 1044 & $523 \& 465$ \\
\hline
\end{tabular}

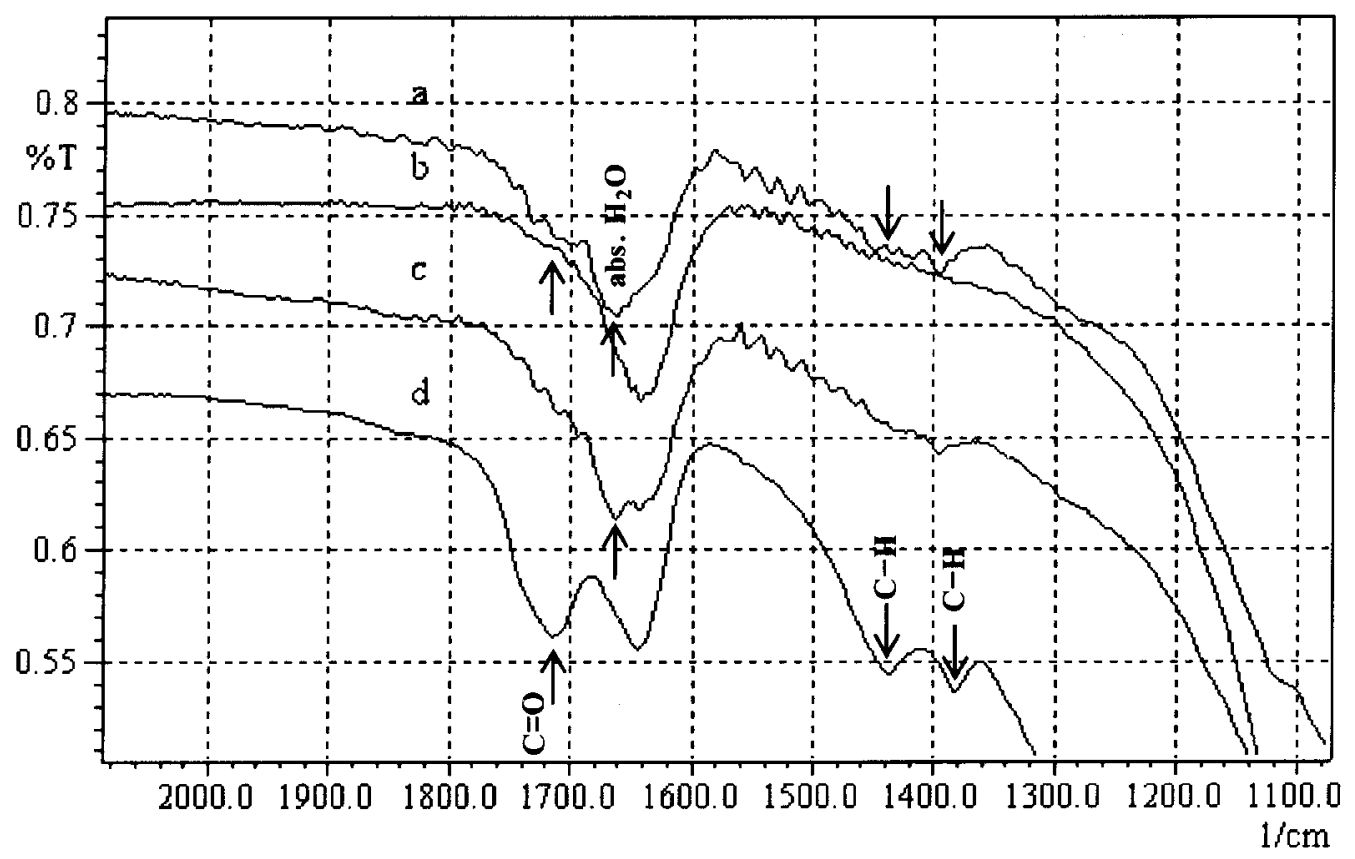

Figure 9. FTIR spectra of $\mathrm{HOH}$ deformation peak region of a. $0.8 \mathrm{~g} / 1$ polyvinyl alcohol adsorbed on Camontmorillonite, b. Ca-montmorillonite, c. $0.4 \mathrm{~g} / \mathrm{l}$ polyvinyl alcohol adsorbed on Ca-montmorillonite and d. $5 \mathrm{~g} / \mathrm{l}$ polyvinyl alcohol adsorbed on Ca-montmorillonite.

table 1 . The position of the deformation band of adsorbed water was changed by the presence of polyvinyl alcohol molecules (table 1, figure 9). When 0.2-1 g/l polyvinyl alcohol was adsorbed on Ca-montmorillonite, the hydroxyl stretching and $\mathrm{Si}-\mathrm{O}$ stretching frequencies broadened and changed only slightly, such as $3627-3625 \mathrm{~cm}^{-1}$ (structural hydroxyl stretching), 3424-3426 $\mathrm{cm}^{-1}$ (OH stretching), $1036-1038 \mathrm{~cm}^{-1}$ ( $\mathrm{Si}-\mathrm{O}$ stretching) and 521-519 and 463$467 \mathrm{~cm}^{-1}$ (Si-O bending), but the FTIR spectra of 1-10 g/l polyvinyl alcohol adsorbed on Ca-montmorillonite showed additional peaks, including $3630-3627 \mathrm{~cm}^{-1}$ (structural hydroxyl stretching), $3424-3418 \mathrm{~cm}^{-1}$ (hydrogen vibration), $1640-1646 \mathrm{~cm}^{-1}$ (HOH deformation) and 1038-1044 $\mathrm{cm}^{-1}$ ( $\mathrm{Si}-\mathrm{O}$ stretching).

The hydroxyl stretching frequencies broadened, and the bands moved to lower frequencies at about $10 \mathrm{~cm}^{-1}$. These shifts might be attributed to the formation of hydrogen bonds. Also the spectra of polyvinyl alcohol adsorbed on Ca-montmorillonite illustrated hydrogen bonding effect clearly in carbonyl stretching region. The residual acetate 
groups-clay complexes showed a shift to lower frequencies $\left(1715 \mathrm{~cm}^{-1}\right)$ for carbonyl stretching vibration, in contrast to the position in the standard polyvinyl alcohol $\left(1734 \mathrm{~cm}^{-1}\right)$. In addition, $\mathrm{Si}-\mathrm{O}$ stretching frequencies broadened and peaks appearing at $1036 \mathrm{~cm}^{-1}$ in montmorillonite's spectrum, moved to $1044 \mathrm{~cm}^{-1}$. These results showed interactions between polyvinyl alcohol molecules and clay particles. Thus, polyvinyl alcohol was loosely bounded and interacted near the surface and/or into the interlayer of montmorillonite.

\section{Conclusions}

Addition of PVA polymer greatly changed the rheological properties of bentonite dispersion. The degree of interaction between polymer molecules and clay particles depended on the polymer concentration in the dispersion. The experiments carried out in this work showed that the rheological and electrokinetic properties of the sample can be brought to desired values by use of PVA concentrations. Thixotropy was observed in bentonite dispersions with/without polymer. As it is known, thixotropy is an important characteristic for industrial applications. For example, drilling fluids and paints must be thixotropic. Thixotropy effect results were in good agreement with the behaviour of bentonite dispersion's yield value. SEM analysis showed a weak association between PVA and bentonite, probably coming from the hydrophobic modification of the clay surface. The particle size and SEM analyses made us think first, face surface and then face and edge surface orientation of the polyvinyl alcohol to the dispersed clay in aqueous solution. Decrease in zeta potential value with increasing PVA concentration emphasized that PVA molecules got attached to the surface of the clay particle. In addition, FTIR spectra confirmed excellent impregnation with the mixture of polyvinyl alcohol molecules and clay particles.

Balikesir (Turkey) bentonite samples have been used in applications for decolourizing or moisture absorption purpose. The PVA/bentonite dispersion has a higher fluidity than bentonite dispersion. The presence of PVA did not prevent extensive swelling of bentonite and they have also led to uses without destroying the applications. In the applications, ease of flow is desired and this PVA bentonite dispersion can be used.

\section{Acknowledgement}

This work was supported by the Research Fund of Istanbul Technical University (project no: 1299).

\section{References}

Alemdar A, Atici O and Güngör N 2000 Mater. Lett. 4357

Cameron G G 1977 in Handbook of synthetic polymers and plastics (eds) J Urbański et al (Poland: Wiley) p. 394

Ece Ö I, Güngör N and Alemdar A 1999 J. Incl. Phenom. Macro. 33155

Günister E, İşci S, Alemdar A and Güngör N 2004 Bull. Mater. Sci. 27317

Güven N C M S 1992 Workshop lectures (Boulder: Clay Minerals Soc.)

Heath D and Tadros Th F 1982 J. Colloidal \& Interface Sci. 93 307

Hunter R J 1986 Foundation of colloid science (New York: Clarendon Press)

İşci S, Günister E, Ece Ö I and Güngör N 2004 Mater. Lett. 58 1975

Lagaly G 1989 Appl. Clay Sci. 4105

Lindemann M K 1971 in Encyclopedia of polymer science and technology (eds) H F Mark et al (New York: Wiley) 14 p. 168

Luckham P F and Rossi S 1999 Adv. Colloid \& Interface Sci. 8243

Neaman A and Singer A 2000 Soil Sci. Soc. Am. J. 64427

Olphen H Van 1977 in Clay colloid chemistry (New York: Wiley)

Tadros Th F 1987 in Solid/liquid dispersions (New York: Academic Press)

Yürüdü C, İşci S, Ünlü C, Atici O, Ece Ö I and Güngör N 2005 Bull. Mater. Sci. 28623 